\title{
Biocompatibility and degradation studies of poly(L-lactide-co-trimethylene carbonate) copolymers as cardiac occluders
}

\section{Laishun Xi, ${ }^{1}$ Yuandou Wang, ${ }^{2}$ Feng Su, ${ }^{1,2 *}$ Qingzhen $\mathrm{Zhu},{ }^{1}$ Suming $\mathrm{Li}^{3 *}$}

${ }^{1}$ State Key Laboratory Base of Eco-chemical Engineering, College of Chemical Engineering, Qingdao University of Science and Technology, Qingdao 266042, China

${ }^{2}$ Institute of High Performance Polymers, Qingdao University of Science and Technology, Qingdao 266042, China

${ }^{3}$ Institut Europeen des Membranes, UMR CNRS 5635, Universite de Montpellier, 34095 Montpellier, France

Correspondence to: F. Su (E-mail: sufeng@qust.edu.cn) and S. Li (E-mail: suming.li@umontpellier.fr)

\begin{abstract}
Poly(L-lactide-co-trimethylene carbonate) (PLT) copolymers were synthesized by ring opening polymerization of L-lactide (LLA) and trimethylene carbonate (TMC). The resulting copolymers were characterized by using ${ }^{1} \mathrm{H}$ NMR, GPC, DSC and tensile tests. The copolymer properties are dependent on the TMC content. In vitro degradation of copolymers was carried out in $\mathrm{pH} 7.4$ phosphate buffered saline at $37{ }^{\circ} \mathrm{C}$. The results show that copolymers with higher TMC content are more resistant to degradation. The cytotoxicity and hemocompatibility of copolymers were evaluated from MTT assay, hemolysis test, dynamic clotting time and plasma recalcification time. Results indicate that the copolymers present very low cytotoxicity and good hemocompatibility.

Cardiac occluders were designed and fabricated using 3D printing. In vivo degradation of occluders was realized by intramuscular implantation in the back of rabbits. The occluders were almost totally degraded in 120 days. Visual observation and H\&E staining analysis confirmed the good tissue compatibility of occluders. All these findings suggest that PLLA-TMC copolymers could be promising for potential applications as degradable occluder
\end{abstract}


material.

Keywords: copolymer; 3D printing; biocompatibility; cardiac occluder; in vitro degradation; in vivo implantation

\section{Introduction}

In the past decades, great progress has been made in the treatment of congenital heart diseases by the use of cardiac occluders. [1-6] Amplatzer occluders are the most widely used occluders in clinical applications. They are double-disc devices made from Nitinol wires tightly woven into two flat discs with a connecting waist. Soft polymeric meshes are placed inside the discs to block the blood stream. These occluders present good short-term curative effect, but the permanent presence of metallic devices in the heart often leads to various adverse reactions such as hemolysis, thrombosis, perforation, allergic skin and dermis, and even neurological complications. [7] Therefore, occluders based on degradable materials have received more and more attention.

BioSTAR occluders use an acellular porcine intestinal collagen layer to replace non degradable meshes. Heparin is coated on the device to reduce protein or blood cell deposition and thrombus formation. But the device cannot be completely resorbed as the framework is made of traditional metals or alloys. [8] Totally degradable occluders have been developed in the past years. Duong et al. developed PFO occluders composed of two self-expanding umbrellas linked by a stem, and 4 spokes to hold the mesh. The device consists of degradable

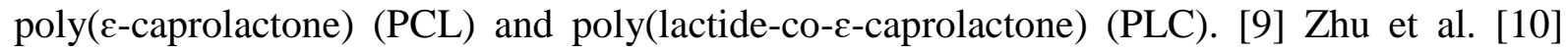
reported Improved Amplatzer occluders made of braided filaments of poly(para-dioxanone) (PDO) and poly(L-lactide) (PLLA) nonwoven fabric as a barrier film. Recently, implantation of totally degradable occluders made of PDO and PLLA was successfully performed in a clinic operation. 
PLLA is a degradable polyester widely used in various biomedical applications such as drug carriers, surgical implants and sutures because of its biocompatibility and mechanical strength. [11] PLLA exhibits good tensile strength up to $60 \mathrm{MPa}$. [12] But PLLA is brittle and highly crystalline, and acidic degradation products can lead to inflammatory reaction. [13,14] Furthermore, non-integrative devices with different degradation times could lead to defect recanalization or abscission of components. Hence, it is of major importance to develop degradable occluders with sufficient strength, good elasticity and integrative design.

The toughness of PLLA based copolymers can be improved by copolymerization of L-lactide (L-LA) with other monomers, such as 1,3-trimethylene carbonate (TMC), glycolide (GA), and $\varepsilon$-caprolactone ( $\varepsilon$-CL). [15,16] Poly(1,3-trimethylene carbonate) (PTMC) is an elastomer with a $\mathrm{T}_{\mathrm{g}}$ of $-15^{\circ} \mathrm{C}$. [17] PTMC degrades extremely slowly by pure hydrolysis, yielding neutral degradation products, i.e., diols and carbon dioxide. In contrast, PTMC rapidly degrades in vivo by enzyme catalyzed surface erosion. [18] PTMC is largely used as a softening component of copolymers for applications as suture material, soft tissue engineering scaffold, and drug carrier due to its flexibility and biocompatibility. [19-21]

PLLA-TMC (PLT) copolymers have been investigated for applications as heart constructs and nerve regeneration guides, [22,23] cartilage implants, [24] and sustained drug release carrier $[25,26]$ In our previous work, copolymers of L-lactide or DL-lactide and TMC with various compositions and chain microstructures were synthesized. The thermal properties, degradation behaviors as well as mechanical properties of the copolymers were studied to evaluate their potential as cardiovascular stent material. [27-29] The results showed that PLT copolymers with high LLA contents exhibit high tensile strength and high crystallinity, but slow degradation rate.

In this paper, PLT copolymers with LLA/TMC molar ratios from 75/25 to 60/40 were synthesized and characterized. The in vitro degradation and biocompatibility of the 
copolymers were investigated to evaluate their potential as degradable occluder material. Occluders of the copolymers were fabricated by 3D printing. The histocompatibility and in vivo degradation of the printed occluders were investigated. The results are reported herein in comparison with literature.

\section{Materials and Methods}

\subsection{Materials}

1,3-propanediol and L-lactic acid were purchased from Tianjin Kemiou Chemical Reagent Co., Ltd (China). Dibutyltin dilaurate, diethyl carbonate, antimony trioxide, zinc powder, sodium metal and stannous octoate $\left(\mathrm{Sn}(\mathrm{Oct})_{2}\right)$ were obtained from Sinopharm Chemical Reagent Co., Ltd (China). The used organic solvents were all of analytic grade.

\subsection{Synthesis}

LLA and TMC monomers were synthesized as previously reported in literature. [30] The crude products were purified by recrystallization in ethyl acetate or mixture of diethyl ether and acetone $(\mathrm{V}: \mathrm{V}=4: 1)$. PLT copolymers were synthesized by ring-opening polymerization of LLA and TMC using stannous octoate as catalyst. [31] Taking PLT 75/25 as example, LLA (32.36 g), TMC (7.64 g) and the catalyst $(0.061 \mathrm{~g})$ were added into a round-bottomed flask, and degassed. The overall comonomers/catalyst ratio was 2000/1. The polymerization was carried out under vacuum at $130^{\circ} \mathrm{C}$ for $72 \mathrm{~h}$. The product was dissolved in dichloromethane, and precipitated in ethanol. Finally the product was thoroughly dried under vacuum at $50^{\circ} \mathrm{C}$ for $72 \mathrm{~h}$.

\subsection{Film and occluder fabrication}

Copolymer films were prepared by solution casting method. [30] The copolymers were dissolved in dichloromethane at $10.0 \mathrm{w} / \mathrm{v} \%$, and the resulting solutions were poured onto a 
glass plate. The solvent was evaporated overnight, followed by vacuum drying for $72 \mathrm{~h}$. The films were then cut into rectangular samples of $10 \times 75 \times 0.2 \mathrm{~mm}$ or square samples of $10 \times 10 \times 0.2 \mathrm{~mm}$ for tensile tests and in vitro degradation studies, respectively.

A 3D occluder model with dumbbell shape and hollow structure was designed using CAD software with parameters of the clinically used devices as reference, and processed using a 3D printer (UN-biomedical 3d printer, Anyprint, China). The printer parameters were set as follows: print temperature $140^{\circ} \mathrm{C}$, nozzle diameter $0.3 \mathrm{~mm}$, discharge speed $0.012 \mathrm{~g} / \mathrm{s}$, printing rate $4 \mathrm{~mm} / \mathrm{s}$, and printing layer thickness $0.2 \mathrm{~mm}$.

\subsection{Characterization}

Proton nuclear magnetic resonance $\left({ }^{1} \mathbf{H}\right.$ NMR). ${ }^{1} \mathrm{H}$ NMR was performed on Bruker AVANCE III 500 spectrometer operating at $500 \mathrm{MHz}$, using deuterated chloroform $\left(\mathrm{CDCl}_{3}\right)$ as a solvent. Chemical shifts $(\delta)$ were given in ppm using tetramethylsilane (TMS) as an internal reference.

Gel permeation chromatography (GPC). GPC was conducted on a Shimadzu apparatus (Waters 410) equipped with a refractometer, using tetrahydrofuran (THF) as mobile phase at a flow rate of $1.0 \mathrm{~mL} / \mathrm{min} .60 \mu \mathrm{L}$ of $1.0 \mathrm{mg} / \mathrm{mL}$ sample solution were injected for measurement, and polystyrene standards were used for calibration.

Differential scanning calorimetry (DSC). DSC was performed using a DSC10 instrument (TA Instruments). $5.0 \mathrm{mg}$ of samples were used for each analysis. A first heating scan was realized from $0^{\circ} \mathrm{C}$ to $200^{\circ} \mathrm{C}$ at $10^{\circ} \mathrm{C} / \mathrm{min}$, followed by fast cooling down to $0^{\circ} \mathrm{C}$ at $50^{\circ} \mathrm{C} / \mathrm{min}$, and a second heating scan to $200^{\circ} \mathrm{C}$ at $10^{\circ} \mathrm{C} / \mathrm{min}$.

Tensile testing. Tensile tests were carried out on a GT-TCS-2000 Universal tensile machine at $25^{\circ} \mathrm{C}$, using rectangular samples of $10 \times 75 \times 0.2 \mathrm{~mm}$. The inductor load capacity was $500 \mathrm{~N}$, and the tensile rate was $50 \mathrm{~mm} / \mathrm{min}$. All results are the average of triplicate measurements. 


\subsection{In vitro degradation}

Square samples with dimensions of $10 \times 10 \times 0.2 \mathrm{~mm}$ were weighed and placed in vials containing $0.1 \mathrm{M} \mathrm{pH}=7.4$ phosphate buffered saline $(\mathrm{PBS})$ at $37^{\circ} \mathrm{C} .0 .01 \%(\mathrm{w} / \mathrm{v})$ sodium azide was added to inhibit the growth of bacteria. At predetermined time intervals, samples were withdrawn from the vials and washed with distilled water. After wiping, the samples were vacuum dried up to constant weight before analyses.

\subsection{Hemocompatibility}

$50 \mathrm{mg}$ of films were immersed in $10 \mathrm{~mL} 0.9 \%$ saline, and stirred 72 hours to obtain extract for hemocompatibility test.

Hemolysis. Hemolysis testing was performed according to the ISO 10993-4-2002 standard, using fresh ACD anticoagulated rabbit whole blood composed of $90 \%$ of blood and $10 \%$ of $3.8 \%$ sodium citrate. Distilled water was taken as positive control, and $0.9 \%$ saline as negative control. $[32,33] 10 \mathrm{~mL}$ of sample extract in a test tube were thermostated at $37^{\circ} \mathrm{C}$ for $30 \mathrm{~min}$. Then $0.2 \mathrm{~mL}$ of diluted blood with blood/saline volume ratio of $4 / 5$ were added into the tubes, and maintained at $37^{\circ} \mathrm{C}$ for $1 \mathrm{~h}$. After incubation, the samples were centrifuged at $3000 \mathrm{r} / \mathrm{min}$ for $5 \mathrm{~min}$. The optical density (OD) of the supernatants was measured at an absorbance wavelength of $545 \mathrm{~nm}$ by using UV spectrophotometer (GBC Cintra 10e, Australia). The hemolytic ratio (HR) was calculated from the OD data of the test sample and controls using the following formula [34]:

$$
\mathrm{HR}(\%)=\left[\left(\mathrm{OD}_{\text {test }}-\mathrm{OD}_{\text {negative }}\right) /\left(\mathrm{OD}_{\text {positive }}-\mathrm{OD}_{\text {negative }}\right)\right] \times 100
$$

Measurements were made in triplicate $(n=3)$.

Dynamic clotting time. A method similar to the work described by Zhang et al. [35] was used for dynamic clotting time measurement. In a test tube were added $10 \mu \mathrm{L}$ of the sample extract and $10 \mu \mathrm{L}$ of $0.2 \mathrm{M} \mathrm{CaCl}_{2}$ solution. After 5 min incubation at $37^{\circ} \mathrm{C}, 80 \mu \mathrm{L}$ of $\mathrm{ACD}$ blood were introduced in the tube. At different time intervals up to $120 \mathrm{~min}, 20 \mathrm{~mL}$ of 
distilled water were carefully added along the tube wall, and the supernatant was collected. The OD value of the supernatant was determined at $490 \mathrm{~nm}$ with a microplate reader (Elx 800 , BioTek, USA). Saline was taken as the negative control, and $0.2 \mathrm{M} \mathrm{CaCl}_{2}$ solution as the positive control. The relative clotting time of samples is obtained from the curves of OD versus time changes. The experiments were repeated five times for each sample $(\mathrm{n}=5)$.

Plasma recalcification time (PRT). The PRT was determined by using Nie's method. [36] Fresh ACD anticoagulated rabbit whole blood was added into an ACD tube, and centrifuged at $3000 \mathrm{r} / \mathrm{min}$ for $10 \mathrm{~min}$ to collect platelet poor plasma (PPP). $0.1 \mathrm{~mL}$ sample extract was added to a test tube, followed by addition of $0.1 \mathrm{~mL}$ PPP. After 2 min incubation in a water bath at $37^{\circ} \mathrm{C}, 0.1 \mathrm{~mL}$ of $0.025 \mathrm{M} \mathrm{CaCl}_{2}$ solution was added. Every 1 or $2 \mathrm{~s}$ the test tube was tilted so as to observe the state of PPP. The clotting time was taken when the plasma solution no longer flowed in the inclined tube. Silicified and unsilicified glass tubes were taken as negative and positive controls, respectively. Triplicate measurements were made for each copolymer sample $(n=3)$.

\subsection{Cytotoxicity}

Both sides of copolymer films $(30 \mathrm{mg})$ were exposed to UV for sterilization at room temperature for $12 \mathrm{~h}$, and then soaked in $5 \mathrm{~mL}$ Dulbecco's Modified Eagle Medium (DMEM). The samples were placed in water bath oscillator at $37^{\circ} \mathrm{C}$ for $72 \mathrm{~h}$ in a sterile environment, followed by centrifugation at $1200 \mathrm{rpm}$ for $5 \mathrm{~min}$. Finally the supernatant was collected for MTT experiment.

MTT test is commonly used to evaluate the cytotoxicity of biomaterials in vitro. [34] L-929 cells (mouse fibroblasts) in the logarithmic growth phase were collected, and diluted with DMEM containing $10 \%$ fetal bovine serum to a cell concentration of $1 \times 10^{4}$ cells $/ \mathrm{mL}$. $100 \mu \mathrm{L}$ cell suspension was added in a well of 96-well plate, and placed in $5 \% \mathrm{CO}_{2}$ incubator at $37^{\circ} \mathrm{C}$. After $24 \mathrm{~h}$ incubation, the culture medium was removed and twice washed with PBS. 
$100 \mu \mathrm{L}$ sample extract was then added. After incubation for 24,48 and $72 \mathrm{~h}$, the supernatant of each well was removed and replaced with $20 \mu \mathrm{L}$ MTT solution at $5 \mathrm{mg} / \mathrm{mL}$ and $80 \mu \mathrm{L}$ DMEM. The liquid in the well was removed after $4 \mathrm{~h}$ incubation. $150 \mu \mathrm{L}$ DMSO was then added, and shaked $10 \mathrm{~min}$. Finally, the OD value was measured at $490 \mathrm{~nm}$ by using microplate reader (Elx800, BioTek, USA). DMEM containing 10\% fetal bovine serum was taken as the negative control, and $6.4 \%$ phenol solution as the positive control. Triplicate measurements were made for all samples. The relative growth rate (RGR) was calculated according to the following formula [37]:

$$
\mathrm{RGR}(\%)=\left(\mathrm{OD}_{\text {test sample }} / \mathrm{OD}_{\text {negative control }}\right) \times 100
$$

The cytotoxicity is generally noted in $0-5$ levels according to the RGR value. Level 0,1 , 2, 3, 4 and 5 corresponds to RGR $\geq 100 \%, 100 \%>$ RGR $\geq 75 \%, 75 \%>$ RGR $\geq 50 \%, 50 \%>$ $\mathrm{RGR} \geq 25 \%, 25 \%>\mathrm{RGR} \geq 1 \%$ and $\mathrm{RGR}>1 \%$, respectively.

\subsection{Histocompatibility and in vivo degradation}

PLT copolymer was processed into occluder samples by 3D printing. The thus obtained samples were soaked in $70 \%$ ethanol for $24 \mathrm{~h}$, and then twice washed by using aseptic PBS. 15 New Zealand white rabbits were anesthetized by injection of $1 \mathrm{~mL} / \mathrm{kg}$ of pentobarbital sodium into the auricular vein. 4 occluders were implanted into the muscle on the back with a distance of no less than $5 \mathrm{~cm}$ between them. The post-operation rabbits were placed in a feeding environment at a temperature of $20 \sim 25^{\circ} \mathrm{C}$ and humidity of $40 \% \sim 60 \%$. At preset time intervals $(10,30,60,90$ and 120 days), three randomly selected rabbits were sacrificed. The occluders were explanted, and the surrounding tissues removed. The tissues were fixed with $10 \%$ formaldehyde solution for $48 \mathrm{~h}$. After rinsing with water, the tissues were dehydrated with a series of ethyl alcohol solutions of $70 \%, 80 \%, 90 \%, 95 \%$ and $100 \%$. Then the tissues were made into the paraffin embedding section of a thickness of $5 \mathrm{~cm}$ for hematoxylin and eosin $(\mathrm{H} \& \mathrm{E})$ staining analysis. The inflammatory reaction and fibrocystic 
cavity formation were observed under the microscope.

The recovered occluder samples were successively immersed in type II collagenase solution $(2.5 \mathrm{~g} / \mathrm{L})$, and trypase solution $(2.0 \mathrm{~g} / \mathrm{L})$ for $1 \mathrm{~h}$. The samples were then rinsed twice with deionized water, and vacuum dried for 1 week up to constant weight. Finally the degraded samples were characterized by using ${ }^{1} \mathrm{H}$ NMR, GPC and DSC.

\section{Result and Discussions}

\subsection{Characterization of copolymers}

A series of PLT copolymers with LLA/TMC molar ratios of 75/25, 70/30, 65/35, and 60/40 were synthesized by ring-opening polymerization, using stannous octoate as initiator. The chemical composition of the copolymers was determined from ${ }^{1} \mathrm{H}-\mathrm{NMR}$ spectra as shown in Figure 1. The signal at $5.20 \mathrm{ppm}$ belongs to the $\mathrm{CH}$ protons of main chain LLA units, and the smaller signal at $5.05 \mathrm{ppm}$ is assigned to the $\mathrm{CH}$ protons of LLA linking to TMC units. [38] The signals of the $\mathrm{CH}_{3}$ protons of LLA are observed in the 1.5-1.60 ppm (b) range. On the other hand, the signals of the methylene groups of TMC units are detected at $2.03 \mathrm{ppm}(\mathrm{d})$ and $4.24 \mathrm{ppm}(\mathrm{c})$, respectively. The LLA/TMC molar ratio of the copolymers was determined from the integration areas of LLA signal at $5.20 \mathrm{ppm}$ and TMC signal at $4.24 \mathrm{ppm}$. As shown in Table 1, the composition of the copolymers is close to the feed ratio, which well

corroborates with high conversion of monomers. The average lengths of lactidyl and carbonate blocks ( $l_{\mathrm{LL}}$ and $l_{\mathrm{TMC}}$, respectively) in PLT polymers were determined from ${ }^{13} \mathrm{C}$ NMR as reported in literature. [27] Both $l_{\mathrm{LL}}$ and $l_{\mathrm{TMC}}$ increase with increase of the corresponding component's content. The $l_{\text {LL }}$ increases from 5.29 for PLT 65/35 to 7.55 for PLT 75/25, whereas $l_{\text {TMC }}$ decreases from 2.70 to 2.57 in the meantime.

GPC was employed to measure the molar masses and dispersity of PLT copolymers as shown in Table 1 . The $\mathrm{M}_{\mathrm{n}}$ varies from 86100 for PLT $60 / 40$ to 113800 for PLT $75 / 25$, and the 
dispersity $\left(\bigoplus=\mathrm{M}_{\mathrm{w}} / \mathrm{M}_{\mathrm{n}}\right)$ varies from 2.0 to 1.8 , in agreement with rather narrow molar mass distribution.<smiles>CC(C)OC(=O)OCCCOC(=O)C(C)OC(=O)C(C)OC(C)(C)C</smiles>

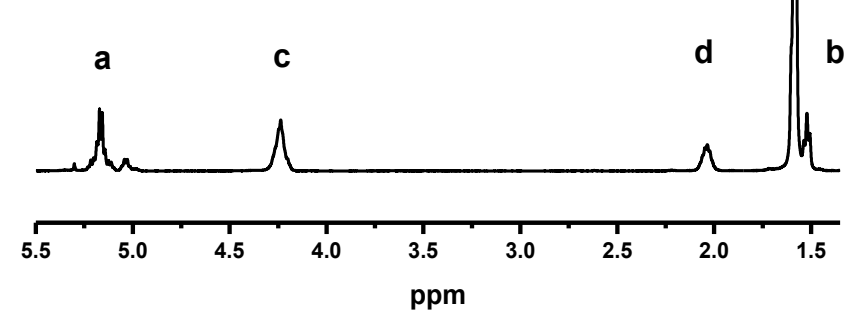

Figure $1 .{ }^{1} \mathrm{H}$ NMR spectrum of PLT 70/30 copolymer in $\mathrm{CDCl}_{3}$.

Table 1. Characteristics of PLLA/TMC (PLT) copolymers.

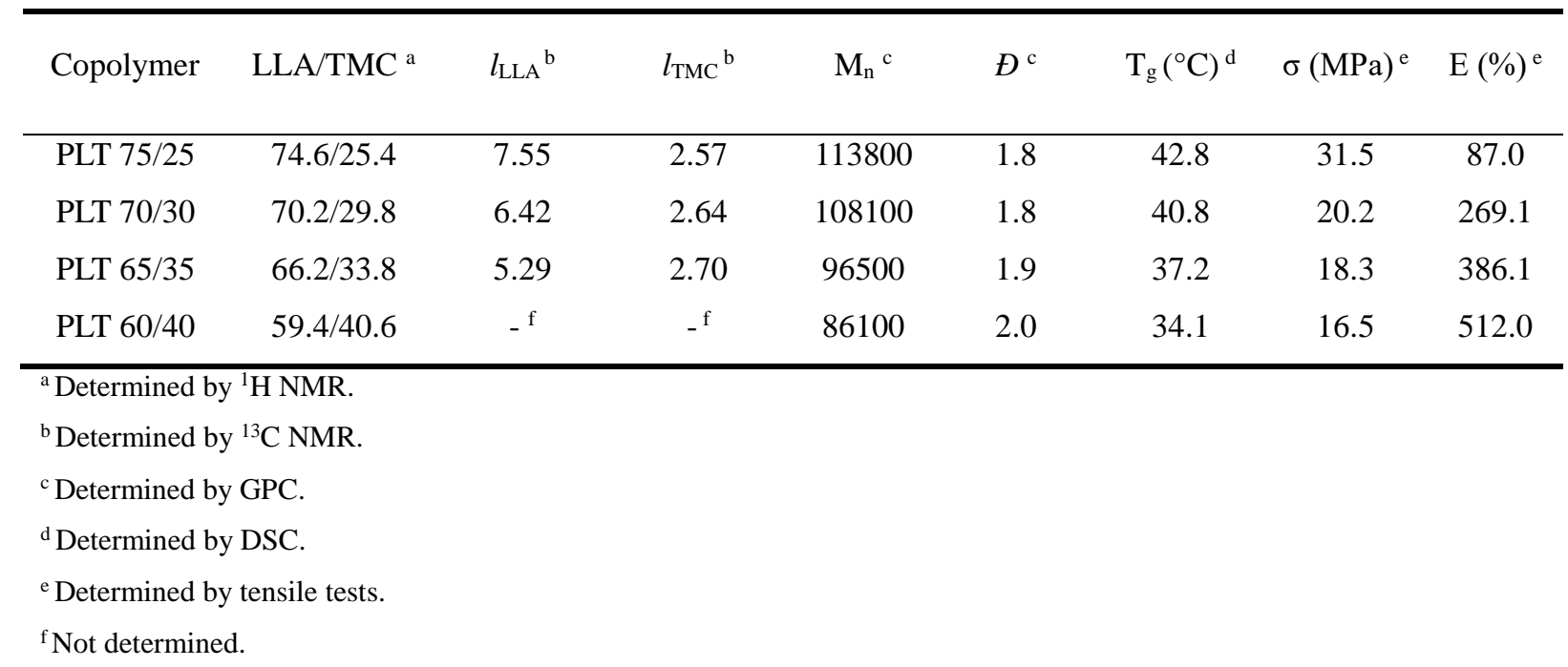

The glass transition temperature $\left(\mathrm{T}_{\mathrm{g}}\right)$ of the copolymers was obtained from DSC (Table 1). All copolymers exhibit only one glass transition temperature, suggesting that the copolymer has a relatively random chain structure. Comparison of the $\mathrm{T}_{\mathrm{g}}$ data shows that the addition of TMC component leads to $\mathrm{T}_{\mathrm{g}}$ decrease from $42.8^{\circ} \mathrm{C}$ for PLT $75 / 25$ to $34.1^{\circ} \mathrm{C}$ for PLT 60/40. This could be assigned to fact that PTMC has lower $\mathrm{T}_{\mathrm{g}}$ and higher chain flexibility 
as compared to PLLA. [39,40] All the copolymers are amorphous as no melting peak was detected. According to the literature, [41] PLLA/TMC copolymers can crystallize when the content of TMC is below $15 \mathrm{~mol} \%$. It has been reported that biomaterials with high crystallinity could lead to late complications such as inflammatory reactions. [18] Thus the amorphousness of PLT copolymers should be beneficial for uses as degradable occluders.

The mechanical properties are of crucial importance for occluder materials. Dong et al. [42] developed PLLA-based terpolymers for applications as biodegradable vascular stent material. Vascular stents should exhibit higher mechanical strength to prevent recoil due to vessel pressure as compared to occluders, and need to support the vessels for about 6 months. In the case of occluders, mechanical support is required for 1-3 months.

The tensile strength $(\sigma)$ and elongation at break $(\varepsilon)$ of PLT copolymers are shown in Table 1. It appears that the composition strongly affect the mechanical properties of copolymers. PLLA homopolymer has a tensile strength of 55.6 $\mathrm{MPa}$ and an elongation at break of 9\%. [41] With introduction of the TMC comonomer, the tensile strength of PLT copolymers decreases from 31.5 MPa for PLT 75/25 to $16.5 \mathrm{MPa}$ for PLT 60/40, the elongation at break increases from $87 \%$ to $512 \%$. The higher the TMC content, the lower the tensile strength, and the higher the elongation at break. Therefore, introduction of flexible TMC component into rigid PLLA chains leads to decrease of the tensile strength and increase of the elongation at break of copolymers.

\subsection{In vitro degradation}

PLT 75/25, PLT 70/30 and PLT 65/65 were selected for in vitro degradation studies. PLT 60/40 was not considered as its $\operatorname{Tg}\left(34.1^{\circ} \mathrm{C}\right)$ is below the body temperature.

Mass loss and water uptake. Mass loss refers to the ratio of soluble species produced during degradation which are dissolved in the medium, and water uptake reflects the content 
of absorbed water in the remaining polymers. Water absorption and mass loss were obtained according to the following equations [32]:

Mass loss $(\%)=100\left(\mathrm{~W}_{\mathrm{i}}-\mathrm{W}_{\mathrm{d}}\right) / \mathrm{W}_{\mathrm{i}}$

Water uptake $(\%)=100\left(\mathrm{~W}_{\mathrm{w}}-\mathrm{W}_{\mathrm{d}}\right) / \mathrm{W}_{\mathrm{d}}$

where $\mathrm{W}_{\mathrm{i}}$ represents the initial weight, $\mathrm{W}_{\mathrm{d}}$ the dry weight after vacuum drying, and $\mathrm{W}_{\mathrm{w}}$ the wet weight of samples after degradation.

Figure 2 presents water uptake and mass loss changes of PLT copolymers during degradation. During the degradation period up to 90 days, $6.5 \%, 4.9 \%$, and $4.7 \%$ of mass loss are obtained for PLT 75/25, PLT 70/30, and PLT 65/35, respectively. Larger difference was observed in water uptake profiles. Water uptake attained nearly $15 \%$ for PLT 75/25 after 90 days, whereas PLT 70/30 and PLT $65 / 35$ had a water uptake of $11 \%$ and $9 \%$, respectively. These findings could be attributed to the fact that PTMC is more resistant to hydrolytic degradation, in agreement with the work reported by Zhang et al. [43] The authors observed that long TMC sequences can be hardly hydrolyzed although PLT copolymers with TMC content above 20 mol\% are amorphous materials.
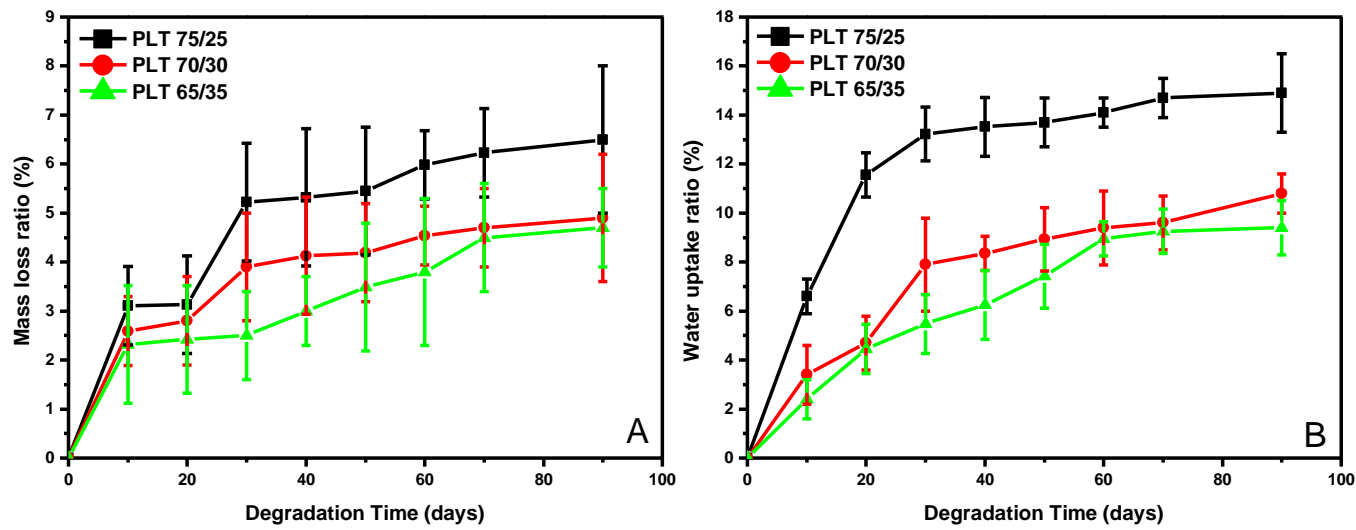

Figure 2. Mass loss (A) and water uptake changes (B) of PLT 75/25, PLT 70/30 and PLT $65 / 35$ during degradation.

Molar mass changes during degradation. The variation of $M_{n}$ during degradation is shown in Figure 3. A molar mass decrease is observed for all samples from the very beginning. 
Actually, water penetrates the PLT samples once immersed in the PBS medium. The chains are cleaved by hydrolysis of ester and carbonate bonds, resulting in the decrease of molar mass. The degradation rate of PLT $65 / 35$ is the slowest, with $\mathrm{M}_{\mathrm{n}}$ continuously decreasing from 96500 to 56900 at 90 days, equivalent to $59 \%$ of the initial value. PLT 70/30 degrades slightly faster than PLT 65/35. The $M_{n}$ decreases from 108100 to 61610 at 90 days, equivalent to $57 \%$ of the initial value. PLT $75 / 25$ shows the fastest decrease of $\mathrm{M}_{n}$ among all the copolymers with $52 \%$ remaining molar mass during the degradation period.

It is worthwhile to point out that polymeric materials lose their mechanical strength when the $\mathrm{M}_{\mathrm{n}}$ is below 25000. [18] The ideal mechanical support time for heart occluders is 2-3 months. Therefore, the three copolymers seem to meet the requirement from the viewpoint of mechanical support during degradation.

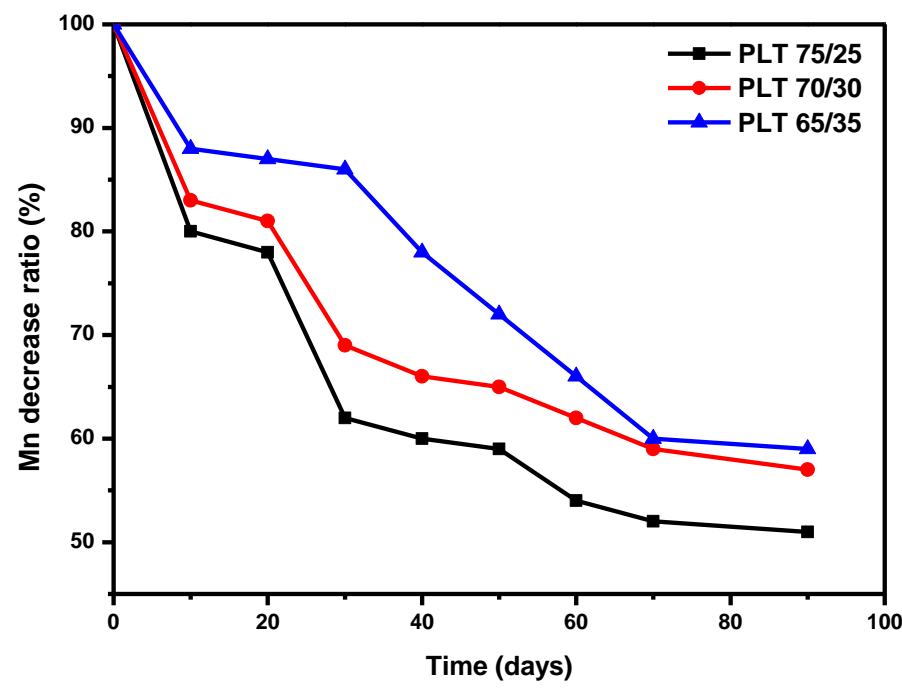

Figure 3. Molar mass decrease ratio of PLT 75/25, PLT 70/30 and PLT 65/35 during degradation.

Compositional changes during degradation. The compositional changes of copolymers during degradation were determined by ${ }^{1} \mathrm{H}$ NMR as shown in Table 2 . The LLA/TMC ratio of PLT 75/25, PLT 70/30, PLT 65/35 decreases from 3.13 to 2.86, from 2.38 to 2.23 , and from 1.94 to 1.82 during 90 days degradation, respectively. In other words, LLA 
units are preferentially degraded because they are more degradable than TMC units, as previously reported in literature. [27,44]

Table 2. LLA/TMC ratio changes of PLT copolymers during in vitro degradation.

\begin{tabular}{cccc}
\hline \multirow{2}{*}{ Time (days) } & \multicolumn{3}{c}{ LLA/TMC ratio } \\
\cline { 2 - 4 } & PLT 75/25 & PLT 70/30 & PLT 65/35 \\
\hline 0 & 3.13 & 2.38 & 1.94 \\
40 & 3.08 & 2.33 & 1.85 \\
60 & 2.94 & 2.30 & 1.84 \\
90 & 2.86 & 2.23 & 1.82 \\
\hline
\end{tabular}

\subsection{Hemocompatibility evaluation}

Hemocompatibility is a key property of biomaterials which are used in contact with blood. Hemolytic ratio, dynamic clotting time and plasma recalcification time were measured to evaluate the hemocompatibility of copolymers.

Hemolysis. Hemolysis test is commonly used for the screening of medical materials. It is generally admitted that a material would not cause hemolysis and can be used for medical applications if the hemolysis ratio is below 5\%, and vice versa. Table 3 presents the hemolysis ratio of the PLT copolymers. The positive control had an absorbance value of 0.707 , whereas the OD value of the negative control group was 0.0033 . These values are within the recommended range of ISO 10993-4. The hemolysis ratio of all samples is well below 5\%, indicating that the copolymers have little effect on the erythrocytes, and are thus safe for medical applications.

Table 3. Hemolysis data of the PLT copolymers.

\begin{tabular}{rcc}
\hline Copolymer & OD value & Hemolysis ratio (\%) \\
\hline PLT 75/25 & $0.0063 \pm 0.0014$ & $0.426 \pm 0.085$ \\
PLT 70/30 & $0.0057 \pm 0.0006$ & $0.340 \pm 0.020$ \\
PLT 65/35 & $0.0084 \pm 0.0006$ & $0.582 \pm 0.164$ \\
PLT 60/40 & $0.0067 \pm 0.0015$ & $0.475 \pm 0.105$ \\
Negative control & $0.0033 \pm 0.0006$ & - \\
\hline
\end{tabular}


Dynamic clotting time. The clotting time allows to evaluate the activation degree of intrinsic coagulation factors, and is thus used to assess the influence of biomaterials on the coagulation process. Absorbance-time curves reflect the coagulation trend of the various samples as shown in Figure 4. The time at which the absorbance equals to 0.1 is generally taken as the clotting time. [45] The initial coagulation time of PLT 75/25, PLT 70/30, PLT $65 / 35$, PLT $60 / 40$ is estimated to be $28,33,35,36 \mathrm{~min}$, respectively, which is shorter than that of the negative control (48 min), but much longer than that of the positive control (6 min). These findings suggest that the copolymers have little effect on the erythrocytes.

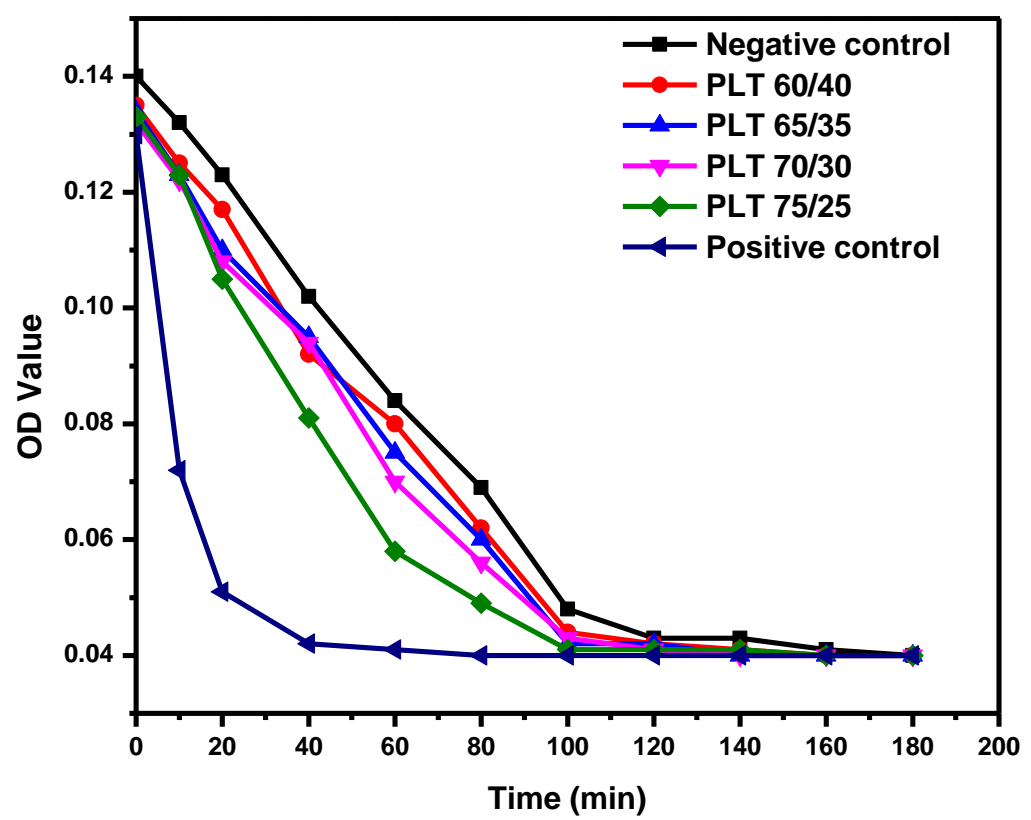

Figure 4. Absorbance-time curves of copolymers in comparison with the controls.

Plasma recalcification time. Plasma recalcification profile allows to measure the time of clot formation in recalcified blood, and can serve as indicator of the intrinsic coagulation system. The plasma recalcification time (PRT) of materials is considered to be significant if it is above $140 \%$ that of the positive control (not silicified glass). [46,47] As shown in Figure 5, the PRT of PLT 75/25, PLT 70/30, PLT 65/35, PLT 60/40 is $279.7 \pm 5.4,322.0 \pm 6.9,342.3 \pm 7.3$ and 335.8 $\pm 9.6 \mathrm{~s}$, respectively. The PRT of copolymers is shorter than that of the negative 
control $(372.6 \pm 10.8 \mathrm{~s})$, but much longer than that of the positive control $(154.3 \pm 9.1 \mathrm{~s})$. Moreover, the PRT of all copolymers is largely above $140 \%$ that of the positive control, thus indicating that they do not have noticeable effect on the intrinsic coagulation pathway.

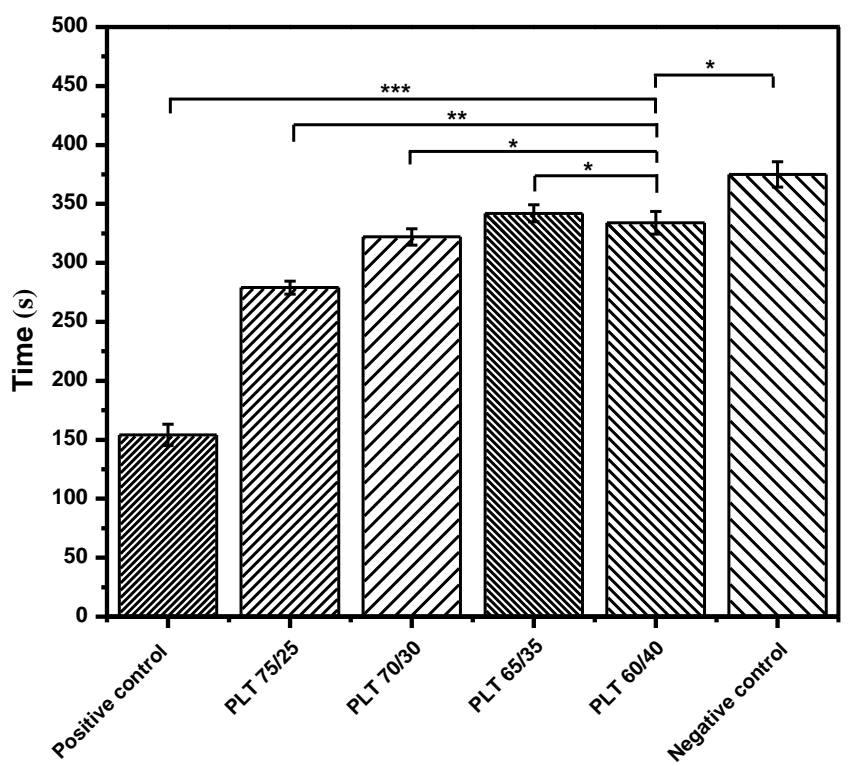

Figure 5. Plasma recalcification time of PLT 75/25, PLT 70/30, PLT 65/35 and PLT 60/40 copolymers. $* *$ indicates $\mathrm{p}<0.01, * * * \mathrm{p}<0.001$, and $* \mathrm{p}>0.05$.

\subsection{Cytotoxicity evaluation}

L-929 cells (mouse fibroblasts) are a commonly used standard cell line for cytotoxicity evaluation of biomaterials which are to be used as medical implants and thus in direct contact with fibroblasts. The cytotoxicity of PLT copolymers was evaluated by using MTT method. [48] Figure 6 shows the viability of cells after co-culture with copolymer extracts for 1, 2 and 3 days. The L-929 cells' viability varies with the incubation time, and the number of L-929 cells reaches a maximum at the second day. The RGR value is above $100 \%$ for all copolymer samples, corresponding to a cytotoxicity level of 0 (Table 4). On the other hand, the survival ratio of the cells in the positive control is very low, and the cytotoxicity level is 4 . These findings show that there was no release of cytotoxic species in the copolymer extracts. 


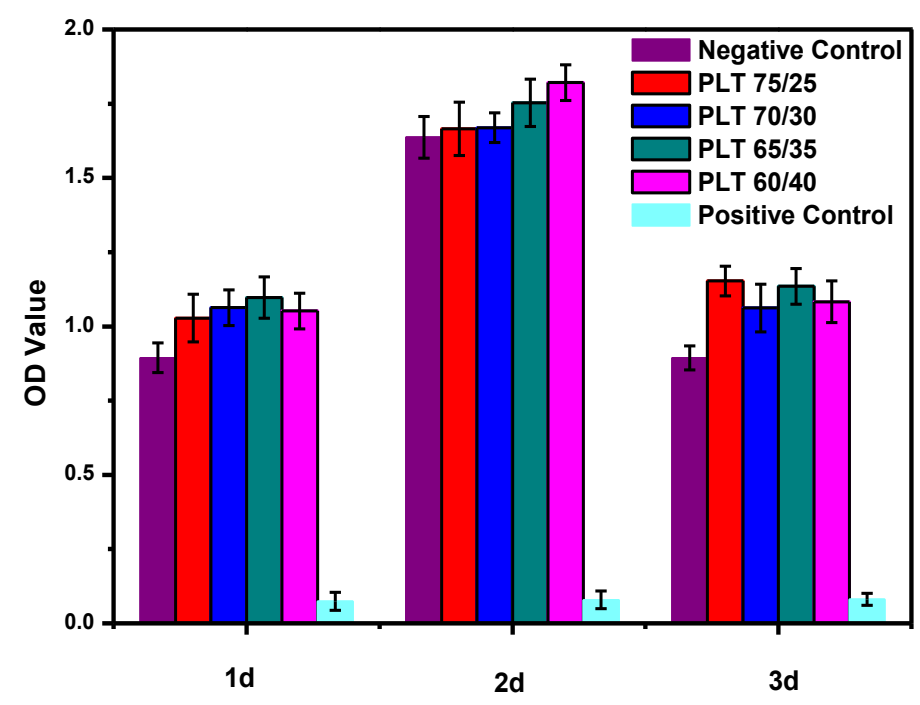

Figure 6. Effect of PLT copolymers on L-929 cells growth in comparison with controls.

Table 4. RGR values and cytotoxicity levels of PLT copolymers during 3 days' incubation with L-929 cells.

\begin{tabular}{ccccccc}
\hline \multirow{2}{*}{ Copolymer } & \multicolumn{2}{c}{$1 \mathrm{~d}$} & \multicolumn{2}{c}{$2 \mathrm{~d}$} & \multicolumn{2}{c}{$3 \mathrm{~d}$} \\
\cline { 2 - 6 } & RGR $(\%)$ & Level & RGR (\%) & Level & RGR (\%) & Level \\
\hline PLT 75/25 & $115.0 \pm 8.7$ & 0 & $101.7 \pm 7.2$ & 0 & $128.9 \pm 12.4$ & 0 \\
PLT 70/30 & $118.9 \pm 5.8$ & 0 & $101.9 \pm 6.3$ & 0 & $118.8 \pm 8.4$ & 0 \\
PLT 65/35 & $122.7 \pm 10.8$ & 0 & $107.1 \pm 5.0$ & 0 & $126.9 \pm 6.8$ & 0 \\
PLT 60/40 & $117.7 \pm 4.7$ & 0 & $111.2 \pm 6.2$ & 0 & $121.1 \pm 11.2$ & 0 \\
Negative Control & 100 & 0 & 100 & 0 & 100 & 0 \\
Positive Control & $8.3 \pm 2.7$ & 4 & $4.8 \pm 1.5$ & 4 & $9.1 \pm 1.8$ & 4 \\
\hline
\end{tabular}

\subsection{In vivo degradation}

PLT 70/30 copolymer was selected for the fabrication of occluder samples by 3D printing due to its outstanding overall properties. A hollow structure with dumbbell shape was designed as shown in Figure 7A. The diameter and the total height are both $12 \mathrm{~mm}$. The thickness of the wall is $0.2 \mathrm{~mm}$. The 3D printed occluder is shown in Figure 7B. The occluder samples were implanted into New Zealand white rabbit muscle tissue, and removed at 10, 30, 60, 90, and 120 days, respectively. No death occurred during the operation. No abnormality, redness or infection was observed in the post-operation period. 

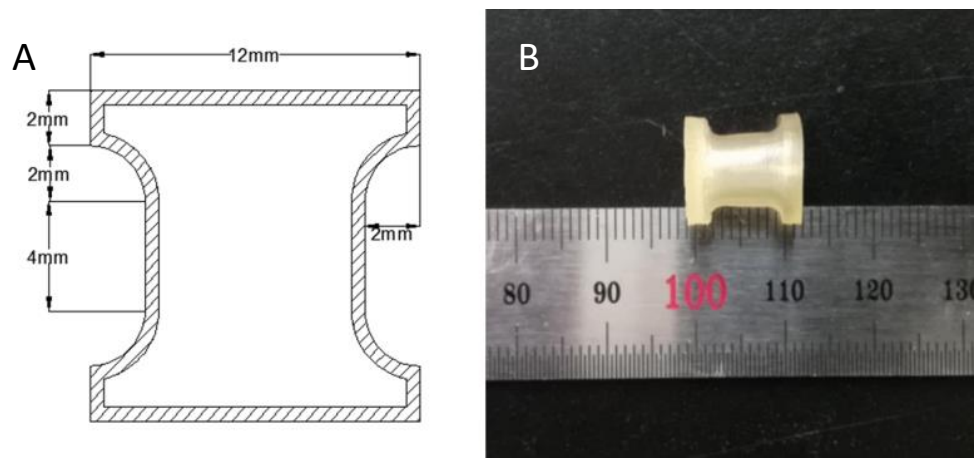

Figure 7. Design (A) and 3D printed occluder sample (B) of PLT 70/30.

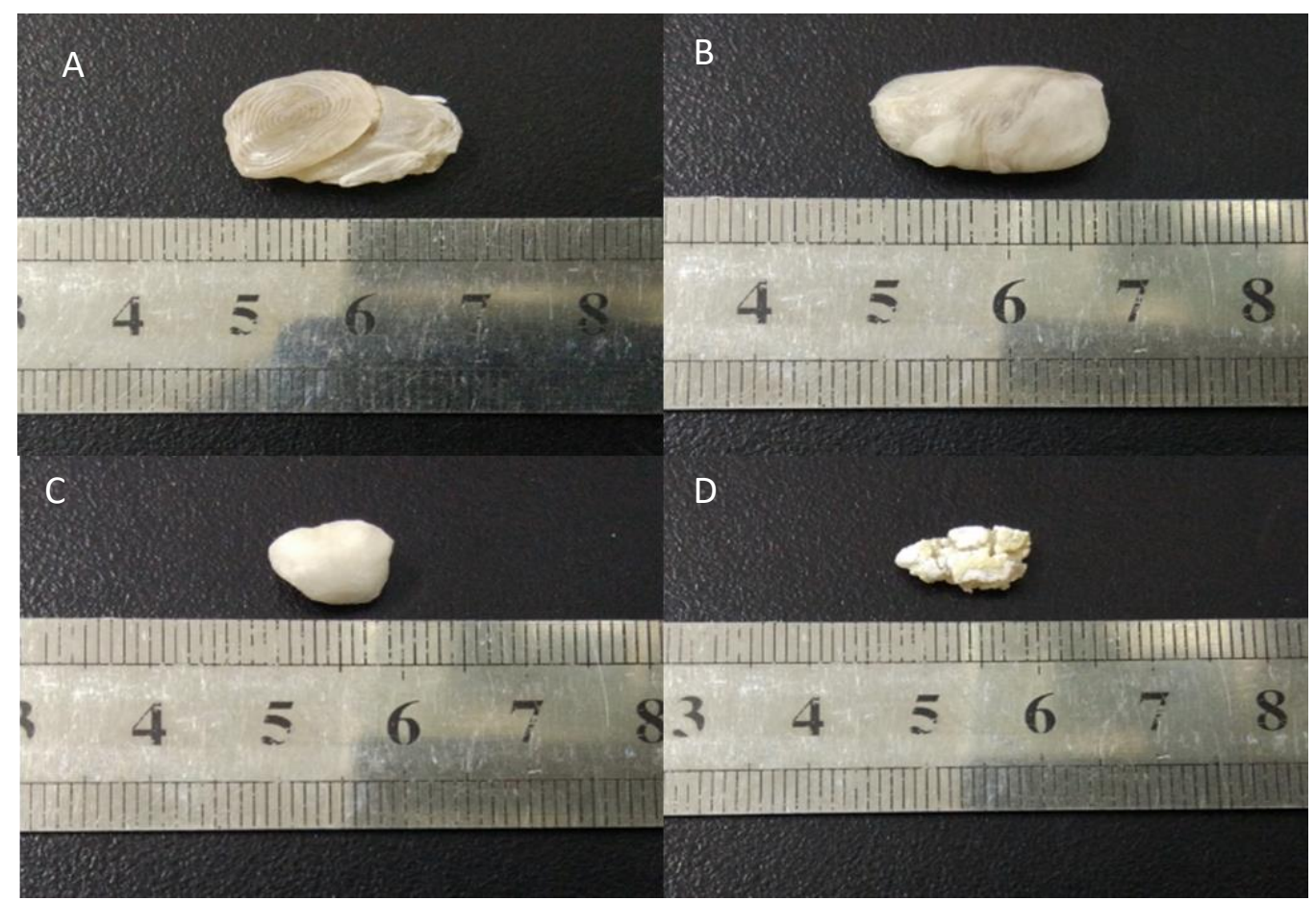

Figure 8. Shape changes during in vivo degradation of the occluders: (A) 10 days; (B) 30 days; (C) 60 days; (D) 90 days.

The occluder appeared flattened after 10 days' implantation as shown in Figure 8A. This phenomenon could be attributed to the fact that the $\mathrm{Tg}$ of the copolymer is only slightly slightly above the body temperature. Thus the copolymer chains have a certain mobility. And with the muscle pressure and movement, the hollow occluder structure collapsed. At 30 days, the occluder became more deformed (Figure 8B). And at 60 and 90 days, the occluder appeared much smaller (Figure 8C, D). Finally at 120 days, the occluder was almost completely degraded, leaving dispersed debris around the muscle tissue. 
Table 5 presents the changes of LLA/TMC ratio, $M_{n}$ and dispersity of occluder samples during in vivo degradation. The $\mathrm{M}_{\mathrm{n}}$ of occluder sample was initially 55970, which was much lower than the value of 108100 of the copolymer. In fact, the 3D printing at high temperature led to a strong Mn decrease, in agreement with thermal degradation of the copolymer. Therefore, 3D printing conditions should be strictly controlled to minimize thermal degradation. Especially, the copolymer should be thoroughly dried prior to processing. A constant decrease of $\mathrm{M}_{\mathrm{n}}$ is observed during degradation from initial 55970 to 1290 at 90 days. The dispersity of molar masses remained almost unchanged. On the other hand, the LLA/TMC ratio decreased continuously from 2.38 initially to 1.92 at 60 days. There findings are consistent with in vitro degradation data, and confirmed faster degradation of LLA units than TMC ones in amorphous zones. Surprisingly, a sharp increase of LLA/TMC ratio up to 4.26 was observed at the last stage of degradation, which could be assigned to crystallization of PLLA segments as shown in Figure 9.

Table 5. Composition and molar mass changes of PLT 70/30 copolymer during in vivo degradation.

\begin{tabular}{cccc}
\hline Time (days) & LLA/TMC ratio $^{\mathrm{a}}$ & $\mathrm{M}_{\mathrm{n}}{ }^{\mathrm{b}}$ & $\Xi^{\mathrm{b}}$ \\
\hline 0 & 2.38 & 55970 & 1.8 \\
10 & 2.22 & 30000 & 1.7 \\
30 & 2.07 & 15500 & 1.5 \\
60 & 1.92 & 10000 & 1.8 \\
90 & 4.26 & 1290 & 1.9 \\
\hline
\end{tabular}

\footnotetext{
${ }^{\mathrm{a}}$ Determined by ${ }^{1} \mathrm{H}$ NMR.

${ }^{\mathrm{b}}$ Determined by GPC.
} 

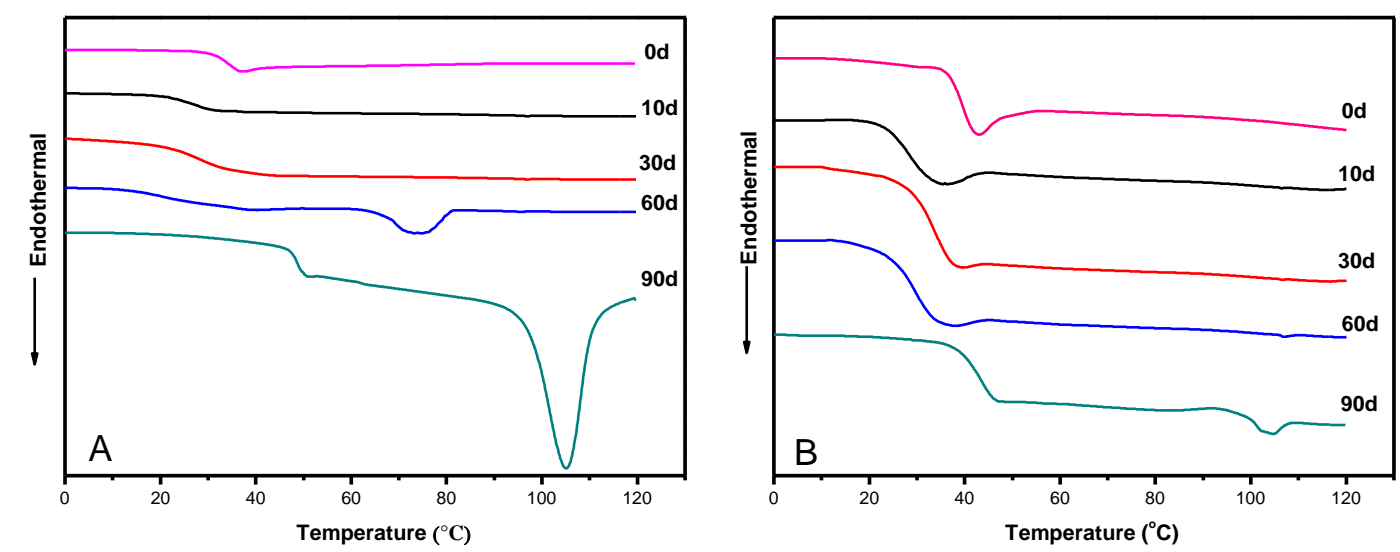

Figure 9. DSC thermograms of PLT 70/30 copolymer after 0, 10, 30, 60, and 90 days in vivo degradation: (A) first heating scan; (B) second heating scan.

It is of interest to follow the morphological changes of the samples during degradation. PLT 70/30 is initially an amorphous copolymer which only exhibits a glass transition. The $\mathrm{T}_{\mathrm{g}}$ determined at the second heating scan shows a gradual decrease from initial $40.5^{\circ}$ to $32.8^{\circ}$ at 60 days. Interestingly, a small endothermic peak is observed at $73.0^{\circ} \mathrm{C}$ with a melting enthalpy $\left(\Delta \mathrm{H}_{\mathrm{m}}\right)$ of $6.8 \mathrm{~J} / \mathrm{g}$ at 60 days, indicating crystallization of degradation by-products. A larger melting peak is detected at $104.1^{\circ} \mathrm{C}$ with a $\Delta \mathrm{H}_{\mathrm{m}}$ of $38.6 \mathrm{~J} / \mathrm{g}$ at 90 days. In fact, PLT 70/30 has a blocky chain structure with a $l_{\mathrm{LL}}$ of 6.42 (Table 1). Thus low molar mass LLA-rich segments produced by degradation are able to crystallize at $37^{\circ} \mathrm{C}$ due to higher chain mobility as compared to long chains, as previously reported in literature. $[27,49,50]$ Once crystallized, the PLLA-rich segments became more resistant to hydrolytic degradation. As a consequence, the LLA/TMC ratio increased at the late stage of degradation. The $\mathrm{T}_{\mathrm{g}}$ also increased from $32.8^{\circ} \mathrm{C}$ at 60 days to $42.6^{\circ} \mathrm{C}$ at 90 days because the $\mathrm{T}_{\mathrm{g}}$ of PLLA is much higher than that of PTMC.

\subsection{Histocompatibility evaluation}

The histological examination at different stages post-implantation is shown in Figure 10. After 10 days, no edema or congestion was observed around the tissue. New tissue began to wrap the sample, and it was not easy to distinguish the boundary between the sample and the 
tissues. The new tissue is predominantly composed of fibroblasts and macrophage cells. But neutrophils, lymphocytes and new capillaries were also observed. At 30 days, the occluder samples were wrapped by a white fiber tissue which formed a loose and rather thick capsule. The capsule was composed of three layers: a foam cell layer near the occluder consisting of degraded copolymer debris phagocytized by macrophages, a middle fibroblast layer, and an outer fibrocellular layer. The three layers were loosely aligned around the occluder. Capillaries and some lymphocytes were observed inside the capsule structure. No edema or hyperemia was observed. At 60 days, the capsule wall became globally thinner and more compact. Thinning of the fibrocellular and fibroblast layers was detected, together with thickening of the foam cell layer and the presence of come multinucleated and plasma cells. At 90 days, the fibrous capsule wall turned thinner and denser, and could be easily detached. The boundaries between the three layers almost disappeared. Similar observations were made at 120 days. Foam cells and a few lymphocytes were found in the capsule.

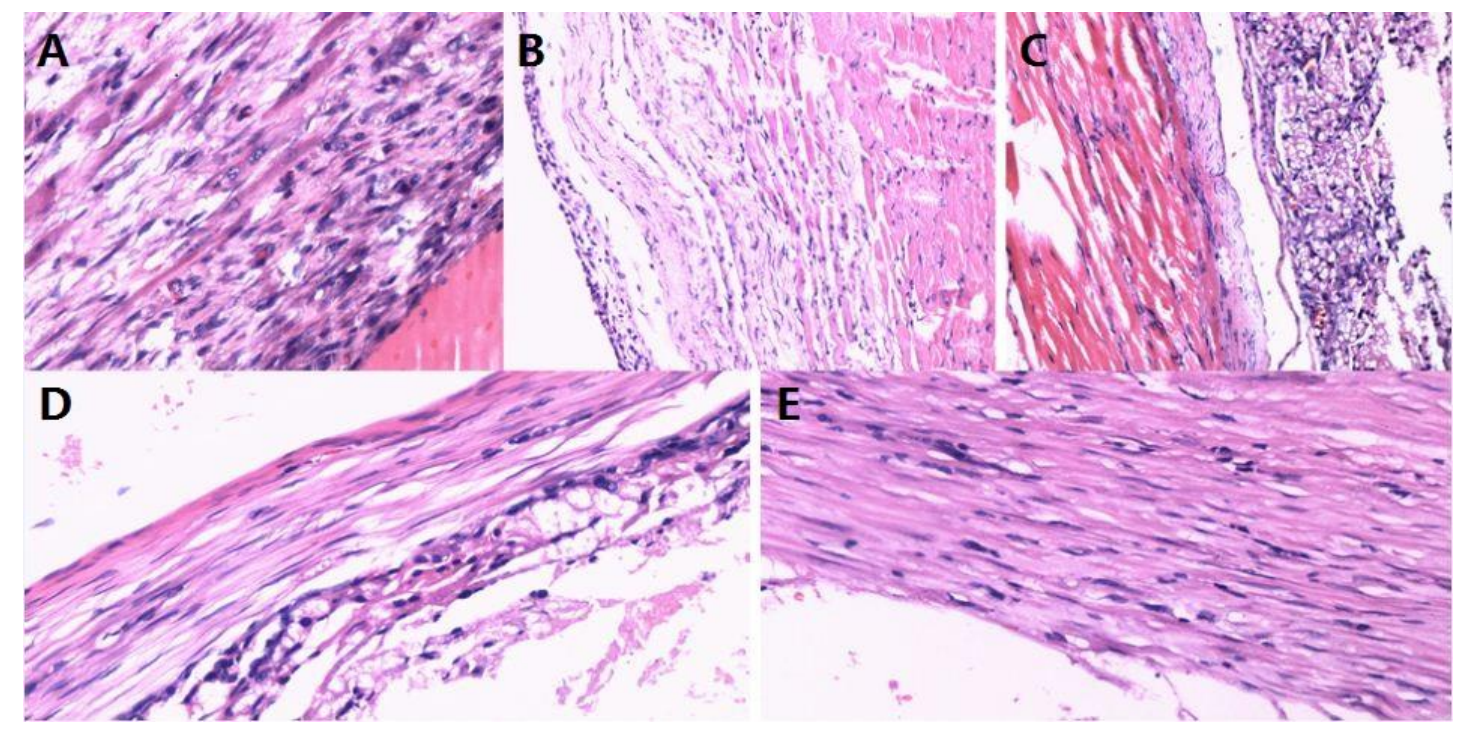

Figure 10. Histological examination at different stages after occluder implantation (original magnification. X200). (A) 10 days; (B) 30 days; (C) 60 days; (D) 90 days; (E) 120 days.

The degradation of PLT copolymer occluders can be divided in two periods. In the first period, the molar mass gradually decreases without weight loss. Inflammatory response was 
detected in the peripheral tissue after 10 days implantation. In the second period from 30 days, weight loss occurred until total degradation of the occluders. Small crystalline particles were obtained during degradation of the material. Meanwhile, macrophages were activated, resulting in the inflammatory reaction. A large number of macrophages englobed the crystalline particles, and thus yielding a foam cell layer. With the time passing by, the foam cells number progressively decreased, and so did the inflammatory reaction. In general, the endothelialization was completed within 3 months of implantation.

Severe inflammatory reactions are not desirable from the histocompatibility aspect. Nevertheless, moderate inflammatory reaction could be helpful to complete endothelialization of the occluder. Cardiac endothelial cells would progressively cover the occluder after implantation, and endothelialization would be completed in 1-3 months. Occluder needs to fulfil its function of blocking and supporting before endothelialization, should be degraded soon after complete endothelialization. If the occluder degrades too quickly, the radial support would quickly decline. Thus the effective support and blocking effect would be deficient. And accumulation of large amounts of degradation products in a short time could lead to occurrence of inflammation and endothelial hyperplasia. On the other hand, if the degradation time is too long, occluders could cause inflammation, and could lead to formation of complications such as thrombosis. Further studies are underway in our group to optimize the copolymer properties, the design of occluder architecture, and the matching of the occluders and the guidewires for potential clinical applications.

\section{Conclusion}

In this work, a series of high molar mass poly(L-lactide-co-trimethylene carbonate) (PLT) copolymers were synthesized and characterized. All copolymers exhibit only one glass transition, and the addition of TMC component leads to $\mathrm{T}_{\mathrm{g}}$ decrease. The tensile strength of copolymers decreases with increasing the content of TMC component, while the elongation at 
break increases. In vitro degradation of PLT copolymers with higher TMC content is slower than that with lower TMC content because TMC units are more resistant to hydrolytic cleavage. The various PLT copolymers present good hemocompatibility and low cytotoxicity as revealed by the hemolysis, dynamic clotting, plasma recalcification and MTT tests.

In vivo degradation was realized by implantation of 3D printed PLT 70/30 occluders in rabbits. Degradation rate was almost completed after 120 days. In particular, crystallization of PLLA degradation by-products was observed. Visual observation and H\&E staining analysis confirmed the good tissue compatibility of occluders. Therefore, PLLA-TMC copolymers could be promising for potential applications as degradable occluder material.

\section{Acknowledgment}

The work is supported by the Science and Technology Development Plan of Shandong Province (2018GGX102016) and the 2018 Shandong Province Graduate Education Joint Training Base Construction Project.

\section{References}

[1] M. Nassif, M. Abdelghani, B. J. Bouma, B. Straver, N. A. Blom, K. T. Koch, J. G. P. Tijssen, B. J. M. Mulder, R. J. De Winter, Historical developments of atrial septal defect closure devices: what we learn from the past, Expert Review of Medical Devices 13 (6) (2016) 555-568.

[2] B. Y. Tang, F. Su, X. K. Sun, Q. Wu, Q. S. Xing, S. M. Li, Recent development of transcatheter closure of atrial septal defect and patent foramen ovale with occluders, Journal of Biomedical Materials Research Part B-Applied Biomaterials 106 (1) (2018) 433-443.

[3] Z. Jalal, S. Hascoet, C. Gronier, F. Godart, L. Mauri, C. Dauphin, B. Lefort, M. Lachaud, D. Piot, M. L. Dinet, Y. Levy, A. Fraisse, C. Ovaert, X. Pillois, J. R. Lusson, J. Petit, A. E. Baruteau, J. B. Thambo, Long-Term Outcomes After Percutaneous Closure of Ostium Secundum Atrial Septal Defect in the Young A Nationwide Cohort Study, Jacc-Cardiovascular Interventions 11 (8) (2018) 795-804. 
[4] M. F. Lopez, B. Krastins, D. A. Sarracino, G. Byram, M. S. Vogelsang, A. Prakash, S. Peterman, S. Ahmad, G. Vadali, W. J. Deng, I. Inglessis, T. Wickham, K. Feeney, G. W. Dec, I. Palacios, F. S. Buonanno, E. H. Lo, M. M. Ning, Proteomic signatures of serum albumin-bound proteins from stroke patients with and without endovascular closure of PFO are significantly different and suggest a novel mechanism for cholesterol efflux, Clinical Proteomics 12 (2015).

[5] C. M. Happel, K. T. Laser, M. Sigler, D. Kececioglu, E. Sandica, N. A. Haas, Single Center Experience: Implantation Failures, Early, and Late Complications After Implantation of a Partially Biodegradable ASD/PFO-Device (BioStar (R)), Catheterization and Cardiovascular Interventions 85 (6) (2015) 990-997.

[6] Y. Y. Huang, J. F. Kong, S. S. Venkatraman, Biomaterials and design in occlusion devices for cardiac defects: A review, Acta Biomaterialia 10 (3) (2014) 1088-1101.

[7] S. F. Rimoldi, S. R. Ott, E. Rexhaj, R. Von Arx, S. F. De Marchi, R. Brenner, U. Scherrer, B. Meier, M. Gugger, Y. Allemann, C. Seiler, Effect of Patent Foramen Ovale Closure on Obstructive Sleep Apnea, Journal of the American College of Cardiology 65 (20) (2015) 2257-2258.

[8] M. J. Mullen, D. Hildick-Smith, J. V. De Giovanni, C. Duke, W. S. Hillis, W. L. Morrison, C. Jux, BioSTAR Evaluation STudy (BEST): a prospective, multicenter, phase I clinical trial to evaluate the feasibility, efficacy, and safety of the BioSTAR bioabsorbable septal repair implant for the closure of atrial-level shunts, Circulation 114 (18) (2006) 1962-7.

[9] D. Duong-Hong, Y. D. Tang, W. Wu, S. S. Venkatraman, F. Boey, J. Lim, J. Yip, Fully Biodegradable Septal Defect Occluder-A Double Umbrella Design, Catheterization and Cardiovascular Interventions 76 (5) (2010) 711-718.

[10] Y. F. Zhu, X. M. Huang, J. Cao, J. Q. Hu, Y. Bai, H. B. Jiang, Z. F. Li, Y. Chen, W. Wang, Y. W. Qin, X. X. Zhao, Animal Experimental Study of the Fully Biodegradable Atrial Septal Defect (ASD) Occluder, Journal of Biomedicine and Biotechnology (2012).

[11]M. Abu Ghalia, Y. Dahman, Biodegradable poly(lactic acid)-based scaffolds: synthesis and biomedical applications, Journal of Polymer Research 24 (5) (2017).

[12]S. Venkatraman, T. L. Poh, T. Vinalia, K. H. Mak, F. Boey, Collapse pressures of biodegradable stents, Biomaterials 24 (12) (2003) 2105-2111.

[13] Y. Ramot, M. Haim-Zada, A. J. Domb, A. Nyska, Biocompatibility and safety of PLA and its copolymers, Advanced Drug Delivery Reviews 107 (2016) 153-162.

[14]N. Saba, M. Jawaid, O. Al-Othman, An Overview on Polylactic Acid, its Cellulosic Composites and Applications, Current Organic Synthesis 14 (2) (2017) 156-170. 
[15]A. Smola, P. Dobrzynski, M. Cristea, J. Kasperczyk, M. Sobota, K. Gebarowska, H. Janeczek, Bioresorbable terpolymers based on L-lactide, glycolide and trimethylene carbonate with shape memory behaviour, Polymer Chemistry 5 (7) (2014) 2442-2452.

[16]A. K. Matta, R. U. Rao, K. N. S. Suman, V. Rambabu, Preparation and Characterization of Biodegradable PLA/PCL Polymeric Blends, Procedia Materials Science 6 (2014) 1266-1270.

[17]C. Zhang, D. H. Liu, X. W. Zhang, P. Wang, Z. Zhen, J. X. Li, D. X. Yi, Y. Jin, D. Yang, Design and in vivo assessment of polyester copolymers based on trimethylene carbonate and epsilon-caprolactone, Journal of Applied Polymer Science 132 (16) (2015).

[18]A. P. Pego, M. J. A. Van Luyn, L. A. Brouwer, P. B. van Wachem, A. A. Poot, D. W. Grijpma, J. Feijen, In vivo behavior of poly (1, 3-trimethylene carbonate) and copolymers of 1, 3-trimethylene carbonate with $\mathrm{D}$, L-lactide or $\epsilon$-caprolactone: Degradation and tissue response, 67 (2003) 1044-1054.

[19]K. Noorsal, M. D. Mantle, L. F. Gladden, R. E. Cameron, Degradation and drug-release studies of a poly(glycolide-co-trimethylene carbonate) copolymer (Maxon), Journal of Applied Polymer Science 95 (3) (2005) 475-486.

[20]B. Y. Yan, Z. P. Zhang, X. P. Wang, Y. F. Ni, Y. S. Liu, T. Liu, W. P. Wang, H. Xing, Y. Sun, J. Wang, X. F. Li, PLGA-PTMC-Cultured Bone Mesenchymal Stem Cell Scaffold Enhances Cartilage Regeneration in Tissue-Engineered Tracheal Transplantation, Artificial Organs 41 (5) (2017) 461-469.

[21]H. Zhao, Y. L. Wang, J. R. Peng, L. Zhang, Y. Qu, B. Y. Chu, M. L. Dong, L. W. Tan, Z. Y. Qian, Biodegradable Self-Assembled Micelles Based on MPEG-PTMC Copolymers: An Ideal Drug Delivery System for Vincristine, Journal of Biomedical Nanotechnology 13 (4) (2017) 427-436.

[22]S. Mukherjee, C. Gualandi, M. L. Focarete, R. Ravichandran, J. R. Venugopal, M. Raghunath, S. Ramakrishna, Elastomeric electrospun scaffolds of poly(l-lactide-co-trimethylene carbonate) for myocardial tissue engineering, Journal of Materials Science-Materials in Medicine 22 (7) (2011) 1689-1699.

[23]C. Marchesi, M. Pluderi, F. Colleoni, M. Belicchi, M. Meregalli, A. Farini, D. Parolini, L. Draghi, M. E. Fruguglietti, M. Gavina, L. Porretti, A. Cattaneo, M. Battistelli, A. Prelle, M. Moggio, S. Borsa, L. Bello, D. Spagnoli, S. M. Gaini, M. C. Tanzi, N. Bresolin, N. Grimoldi, Y. Torrente, Skin-derived stem cells transplanted into resorbable guides provide functional nerve regeneration after sciatic nerve resection, Glia 55 (4) (2007) 425-38.

[24]N. Andronova, A. C. Albertsson, Resilient bioresorbable copolymers based on 
trimethylene carbonate, L-lactide, and 1,5-dioxepan-2-one, Biomacromolecules 7 (5) (2006) 1489-95.

[25]K. Jelonek, J. Kasperczyk, S. M. Li, P. Dobrzynski, B. Jarzabek, Controlled poly(L-lactide-co-trimethylene carbonate) delivery system of cyclosporine $\mathrm{A}$ and rapamycine - the effect of copolymer chain microstructure on drug release rate, International Journal of Pharmaceutics 414 (1-2) (2011) 203-209.

[26]K. Jelonek, B. Kaczmarczyk, J. Jaworska, M. Pastusiak, M. Sobota, P. Dobrzynski, J. Kasperczyk, The influence of drug-polymer interactions on release of antirestenotic agent from bioresorbable scaffolds, Materials Letters 223 (2018) 82-85.

[27]J. J. Hua, K. Gebarowska, P. Dobrzynski, J. Kasperczyk, J. Wei, S. M. Li, Influence of chain microstructure on the hydrolytic degradation of copolymers from 1,3-trimethylene carbonate and L-lactide, Journal of Polymer Science Part A-Polymer Chemistry 47 (15) (2009) 3869-3879.

[28]J. Yang, F. Liu, L. Yang, S. M. Li, Hydrolytic and enzymatic degradation of poly(trimethylene carbonate-co-D,L-lactide) random copolymers with shape memory behavior, European Polymer Journal 46 (4) (2010) 783-791.

[29]Q. K. Guo, Z. Q. Lu, Y. Zhang, S. M. Li, J. Yang, In vivo study on the histocompatibility and degradation behavior of biodegradable poly(trimethylene carbonate-co-D,L-lactide), Acta Biochimica et Biophysica Sinica 43 (6) (2011) 433-440.

[30]L. Liao, J. T. Dong, L. Shi, Z. Y. Fan, S. M. Li, Z. Q. Lu, In vitro degradation behavior of L-lactide/trimethylene carbonate/glycolide terpolymers and a composite with poly(L-lactide-co-glycolide) fibers, Polymer Degradation and Stability 111 (2015) 203-210.

[31]H. L. Li, J. P. Chang, Y. Y. Qin, Y. Wu, M. L. Yuan, Y. J. Zhang, Poly(lactide-co-trimethylene carbonate) and Polylactide/Polytrimethylene Carbonate Blown Films, International Journal of Molecular Sciences 15 (2) (2014) 2608-2621.

[32]E. A. Bender, M. D. Adorne, L. M. Colome, D. S. P. Abdalla, S. S. Guterres, A. R. Pohlmann, Hemocompatibility of poly(epsilon-caprolactone) lipid-core nanocapsules stabilized with polysorbate 80-lecithin and uncoated or coated with chitosan, International Journal of Pharmaceutics 426 (1-2) (2012) 271-279.

[33]S. Manju, K. Sreenivasan, Gold nanoparticles generated and stabilized by water soluble curcumin-polymer conjugate: Blood compatibility evaluation and targeted drug delivery onto cancer cells, Journal of Colloid and Interface Science 368 (2012) 144-151.

[34]F. Su, X. Shen, Y. F. Hu, V. Darcos, S. M. Li, Biocompatibility of thermo-responsive 
PNIPAAm-PLLA-PNIPAAm triblock copolymer as potential drug carrier, Polymers for Advanced Technologies 26 (12) (2015) 1567-1574.

[35]E. L. Zhang, H. Y. Chen, F. Shen, Biocorrosion properties and blood and cell compatibility of pure iron as a biodegradable biomaterial, Journal of Materials Science-Materials in Medicine 21 (7) (2010) 2151-2163.

[36]Y. Nie, Y. Duan, Z. Zhang, Evaluation of blood compatibility of surface modification treated poly (D, L-lactic and glycolic acid) with mPEG block copolymer, Journal of Biomedical Engineering 24 (2) (2007) 336-9.

[37]Z. Q. He, L. Z. Xiong, In-vitro Response of Fibroblasts to Poly-L-lactide Composite Materials Containing Bovine Bone, Polymers \& Polymer Composites 20 (6) (2012) 531-535.

[38]U. Krumsdorf, S. Ostermayer, K. Billinger, T. Trepels, E. Zadan, K. Horvath, H. Sievert, Incidence and clinical course of thrombus formation on atrial septal defect and patient foramen ovale closure devices in 1,000 consecutive patients, Journal of the American College of Cardiology 43 (2) (2004) 302-9.

[39]L. Liao, J. T. Dong, G. X. Wang, Z. Y. Fan, S. M. Li, Z. Q. Lu, Microstructure-property relationship of L-lactide/trimethylene carbonate/glycolide terpolymers as cardiovascular stent material, European Polymer Journal 66 (2015) 429-436.

[40]X. Zhang, M. A. Geven, D. W. Grijpma, J. E. Gautrot, T. Peijs, "Polymer-polymer composites for the design of strong and tough degradable biomaterials", Materials Today Communications 8 (2016) 53-63.

[41]J. T. Dong, L. Liao, L. Shi, Z. S. Tan, Z. Y. Fan, S. M. Li, Z. Q. Lu, A bioresorbable cardiovascular stent prepared from L-lactide, trimethylene carbonate and glycolide terpolymers, Polymer Engineering and Science 54 (6) (2014) 1418-1426.

[42] J. T. Dong, L. Liao, Y. Ma, L. Shi, G. X. Wang, Z. Y. Fan, S. M. Li, Z. Q. Lu, Enzyme-catalyzed degradation behavior of L-lactide/trimethylene carbonate/glycolide terpolymers and their composites with poly(L-lactide-co-glycolide) fibers, Polymer Degradation and Stability 103 (2014) 26-34.

[43]Z. Zhang, R. Kuijer, S. K. Bulstra, D. W. Grijpma, J. Feijen, The in vivo and in vitro degradation behavior of poly(trimethylene carbonate), Biomaterials 27 (9) (2006) 1741-1748.

[44]Y. R. Han, Z. Y. Fan, Z. Q. Lu, Y. Zhang, S. M. Li, In vitro Degradation of Poly[(L-lactide)-co-(trimethylene carbonate)] Copolymers and a Composite with Poly[(L-lactide)-co-glycolide] Fibers as Cardiovascular Stent Material, Macromolecular 
Materials and Engineering 297 (2) (2012) 128-135.

[45]J. Li, W. Zheng, Y. F. Zheng, X. Lou, Cell responses and hemocompatibility of g-HA/PLA composites, Science China-Life Sciences 54 (4) (2011) 366-371.

[46]B. C. Dash, G. Rethore, M. Monaghan, K. Fitzgerald, W. Gallagher, A. Pandit, The influence of size and charge of chitosan/polyglutamic acid hollow spheres on cellular internalization, viability and blood compatibility, Biomaterials 31 (32) (2010) 8188-8197.

[47]Q. S. Zhu, L. B. Chen, P. Y. Zhu, J. F. Luan, C. Mao, X. H. Huang, J. Shen, Preparation of PNIPAM-g-P (NIPAM-co-St) microspheres and their blood compatibility, Colloids and Surfaces B-Biointerfaces 104 (2013) 61-65.

[48] Y. L. Luo, C. H. Zhang, F. Xu, Y. S. Chen, Novel THTPBA/PEG-derived highly branched polyurethane scaffolds with improved mechanical property and biocompatibility, Polymers for Advanced Technologies 23 (3) (2012) 551-557.

[49]M. Therin, P. Christel, S. Li, H. Garreau, M. Vert, In vivo degradation of massive poly ( $\alpha$-hydroxy acids): validation of in vitro findings, Biomaterials 13 (1992) 594.

[50]J. Fernandez, A. Larranaga, A. Etxeberria, J. R. Sarasua, Effects of chain microstructures and derived crystallization capability on hydrolytic degradation of poly(L-lactide/epsilon-caprolactone) copolymers, Polymer Degradation and Stability 98 (2) (2013) 481-489. 


\section{Declaration of interest}

On behalf of all authors, I declare that there are no Conflicts of Interest in this work.

Suming LI

July $2^{\text {nd }}, 2019$ 